\title{
Title: Waterfront Toronto: Privacy or Piracy?
}

\author{
NAme: Kyle Peel and Eliot Tretter \\ DEPARTMENT OF GEOGRAPHY, UNIVERSITY OF CALGARY
}

\begin{abstract}
:
Toronto's Portlands neighborhood is the target of an enormous redevelopment effort that will infuse smart-city technologies into the urban morphology. The quasi-governmental Waterfront Toronto agency has partnered with the Alphabet subsidiary company Sidewalk Labs to plan and build out the neighborhood, essentially from the ground up, and embedded it with sophisticated technologies. The redevelopment plan details a digital layer made up of sensors that will collect and process locational information, tracking movement and usage patterns. Yet the project has been mired in controversy, mainly because of questions about data ownership and management. While there will be the amassing of an unfathomable amount of data, it is not clear who will control it and how it will be processed and used. Critics of the project have pointed out that the potential value of the data is enormous and if a private company has exclusive domain over it, that company could decide to sell it at will. Securely storing citizen's data is another problem. This paper provides a description of the popular newspaper accounts of the Waterfront Toronto Project. It discusses how the project and redevelopment authority came to be, how Alphabet became the primary partner, the redevelopment vision, and controversy that has engulfed this smart-city project.
\end{abstract}

Keywords: [Smart Cities, data generation, urban development, digital privacy, Canadian cities]
The Waterfront Toronto Project is the first of its kind in Canada and will potentially be a precedent-setting case for private-public partnerships and data collection in smart cities in North America. This paper describes the Waterfront Toronto project from conception to the present. It focuses on the redevelopment plan, the proposed systems of data generation and collection, and the controversy surrounding the project. The purpose of this paper is to summarize popular news sources, both nationally and internationally. For this study about 870 newspaper articles from 2014-2019 that mention the term "Sidewalk Toronto" were surveyed. The only primary source consulted was the Waterfront Project Vision, the planning document released by Sidewalk Labs in 2017.

As part of Canada's 2008 bid to host the Summer Olympics in Toronto, thenPrime Minister Jean Chrétien, Premier Mike Harris, and Mayor Mel Lastman announced the creation of a task-force that would oversee, and advise on, redevelopment on Toronto's waterfront. When the International Olympic Committee awarded Beijing the bid, the three divisions of government decided that Toronto's waterfront revitalization should proceed. In November 2001 the Toronto Waterfront Revitalization Corporation (later renamed Waterfront Toronto) was formed and tasked with supervising all planning and development of associated

Citation: Peel, Kyle \& Eliot Tretter (2019) Waterfront Toronto: Privacy or Piracy? UCCities Working Paper \# 2. DOI: $10.31235 / 0$ ff.io/xgz2s.

Articles published as UCCities working papers are licensed under a Creative Commons Attribution-NonCommercial-ShareAlike 4.0 International License. 
projects within the over 800 hectares of land in and around Toronto's Portlands (Cherney, 2001). In fact, this is considered one of North America's largest areas of underdeveloped urban land ("New," 2017). The area is known for derelict buildings, a lack of private investment, and a dearth of regular visitors (Pringle, 2017).

More than a decade and a half after the formation of the Corporation, in March 2017, Waterfront Toronto issued a request for proposals (RFP) regarding the development on 12 acres of land within its Portlands area remit (McConnell, 2017). Ten months prior, Dan Doctoroff, Sidewalk Labs' CEO and co-founder, had announced that Sidewalk was looking to find a large-scale urban district to act as a test bed for its smart technology in Toronto (Rider, 2017). Sidewalk Labs is a subsidiary of Alphabet, made up of a team of urban experts who helped guide New York City's post-9/11 resurgence. Their work is distinguished by their efforts to interweave urban spaces with advanced technology (New, 2017). Sidewalk offered its services to Waterfront Toronto when the RFP was announced, and by as early as May 2017 it was reported that the company's proposal was being considered for the bid (Bergen, 2017). By early October, it was reported that Sidewalk Labs was in-fact close to completing a deal with Waterfront Toronto (GeorgeCosh \& Brown, 2017).

On October 18, 2017, the public-private partnership between Sidewalk and the Waterfront was officially announced in Corus Quay, on the eastern waterfront. Will Fleissig and Dan Doctoroff, Sidewalk Labs' two CEOs, made the official announcement, with Canadian Prime Minister Justin Trudeau, Ontario Premier Kathleen Wynne, and Toronto Mayor John Tory all in attendance. The federal, provincial, and municipal governments had recently committed a combined $\$ 1.25^{B}$ to Waterfront Toronto to provide flood protection and infrastructure improvement in the area. Now Sidewalk was committing an additional $\$ 50 \mathrm{M}$ in initial funding for joint planning and pilot project testing (George-Cosh, 2017). Soon after the announcement, Sidewalk Labs released a planning document that presented the project's future (Waterfront Project Vision, 2017). Overall, the plan split the redevelopment into two parts: the physical layer and the digital layer.

The physical layer is broken up into four subsections: buildings, mobility, the public realm, and infrastructure. Sidewalk's vision for the Waterfront consists of mixeduse flexible spaces that can easily mutate as user needs change. The company's modular concept is centered around building designs that are supple and reconfigurable (Waterfront 110). The flexible loft concept is described as being one in which all users are provided with a base design that can be readily altered. Its plan delineates between two different styles of loft: the 'core loft' and the 'next-gen bazaar.' The core lofts change with the community's needs and could span months or years. A parking garage space, for example, could change as a result of less automobile dependence. Floors needed for parking in 2019 might evolve into retail space by 2029. The 'next-gen bazaar,' meanwhile, is distinguished by retail spaces that are malleable and receptive to daily changes. Examples of this kind of temporary use may include a tech start-up that needs a collective workspace only for a day or two or a fashion pop-up hosting a one-day sale.

Mobility is also one of the central aspects and innovations of Sidewalk Lab's Waterfront planning vision. From increasing pedestrian and cyclist walkways to introducing new automated, driverless transportation, the Waterfront will be redeveloped to be a 
testbed for the rollout and implementation of new smart-city technologies that increase traffic throughput, reduce congestion, and increase the availability and safety of all transit options. Sidewalk intends to use sensors to track and collect data on transit infrastructure usage, even by pedestrians and cyclists, in order to allow site managers to understand local traffic dynamics, locate potential bottlenecks, and monitor and solve problems that arise. For example, Sidewalk is planning to use a special on-demand traffic space allocation system where LED lights can switch to indicate that lanes have become pedestrian lanes (Waterfront 28). Moreover, Waymo, another subsidiary of Alphabet, is developing a taxibot network to be a significant source of motor traffic within the area (Ohnsman, 2017). Finally, a 'managed parking' system will control and direct where automobiles can park. In addition to reducing ambient emissions, this will mitigate congestion, allowing narrower roads to become more utilized, and free up spaces for pedestrians and cyclists. Within the Waterfront development, Sidewalk planners anticipate the use of personal vehicles will be 15 percent of trips while 35 percent will be walking and cycling; currently, on average, Torontonians use personal vehicles for about 55 percent of their trips and walking or biking for about 15 percent. (Waterfront 133).

In order to create a more desirable public realm, the company wants to utilize a range of new weather-mitigating technologies and all-seasons infrastructure to draw people outdoors year-round (Waterfront 19). For example, Sidewalk plans to place retractable canopies in public spaces throughout the area and use heated bike and pedestrian paths to melt snow.

The final aspect of the physical layer is infrastructural improvements that will be placed mostly underground, beneath the city streets. A network of underground utility channels will be built to house electrical wiring, telecommunication conduits, and plumbing pipelines, as well as provide the core system for the circulation of small-scale robots to move among buildings and complete deliveries (Waterfront 23). Examples of this include ClearPath and Amazon's Kiva, where autonomous robots are being designed to move packages and waste throughout communities (Waterfront 145). Sidewalk suggests they will virtually eliminate the need for delivery vehicles and waste-removal trucks, thereby freeing up the streets for more pedestrian traffic.

Sidewalk Labs' proposal for the community's digital layer is equally ambitious and made up of four components: sense, model, map, and account. The sense feature is comprised of a network of sensors that will collect real-time data about the environment and residents in order to measure and provide more precise knowledge about how people are interacting with the space. The model component will simulate 'what if' scenarios and learn from the collected data, which will then be used to improve longerterm planning decisions. The map component will involve the collection of a variety of locational information, often at a fine-grain scale, gleaned from the recording of the neighborhood. Finally, the account feature will provide special portals that will allow residents or renters to access place-specific services. For example, residents will be able to use the portals remotely to give maintain workers access to their homes for necessary services.

About four months after the official announcement of Waterfront Toronto's formation, the motivation for Alphabet's and Sidewalk Labs' involvement in the project began to come into question. Numerous 
Toronto city councillors began to criticize the secrecy surrounding the deal, particularly Waterfront Toronto's refusal, for 'commercial reasons,' to release the text from the agreement in October (Gray, 2018a). Critics also noted that as data is becoming an increasingly valuable commodity, it was not clear what rights were being granted to Alphabet private companies regarding the use and processing of the data it collected (Kane, 2018a). In an attempt to address these concerns and placate increasingly vocal criticism, Sidewalk held a public roundtable discussion. This public-relations effort seemed to assuage some critics on the issue of transparency, but the thornier issue of who would own the data and where it would be housed remained unaddressed (Gray, 2018b). In a move to further mollify critics, Waterfront Toronto appointed an independent advisory panel, headed by Michael Geist, a distinguished law professor from the University of Ottawa (Gray, 2018c).

In early September, reports surfaced that Sidewalk Labs was stipulating that any building-design partners had to hand over all the intellectual property rights on their designs. In other words, Sidewalk would be granted all potential future revenues from the further commercialization of design innovations implemented in the area. Critics again charged that Toronto, and Canada, may not be getting their fair share from the intellectual property. Then in the fall of 2018, the tumult escalated following the resignation from the advisory panel of Ann Cavoukian (a former Ontario privacy commissioner), Julie Di Lorenzo (a member of Waterfront's board), and two digital-strategy advisers, Saadia Muzaffar and John Ruffolo. All claimed to have significant concerns about Sidewalk's heavy-handed approach. Especially damming were Cavoukian's parting comments: "I wanted this to become a smart city of privacy - not a smart city of surveillance" (Kane, 2018b).

Under increasing attack, Sidewalk responded by releasing a more detailed site plan in November 2018. The company also insisted it was committed to creating nearly 4000 jobs in Toronto and that at least 20 percent of the new housing built in the community would be affordable (Boxikovic \& Kane, 2018). However, critics remained unappeased. They underscored that Sidewalk had again failed to reveal any specific plans regarding data ownership or control within Waterfront.

The imbroglio continued to escalate. A few weeks after the release of the detailed site plan Ontario's auditor-general found that Waterfront Toronto had given Sidewalk Labs special treatment during the RFP selection process. The report pointed out that numerous parts of the process had been rushed and not allowed time for sufficient public-sector input (Kane, 2018c). Almost immediately, Ontario's government announced that the three provincially appointed directors on Waterfront's board would be fired (Kane, 2018d). Intragovernmental tensions flared. In opposition to the Province, the municipal and federal governments came out in support of the fired board members. However, Sidewalk Toronto capitulated, choosing to honor the wishes of the Provincial government and remove the directors (Kane, 2018e). Finally, the situation came to a head in mid-February 2019 when Waterfront's business plan was leaked to the press. Its contents were scintillating, revealing plans for the development of talltimber buildings and the expansion of Toronto's transit system to the redevelopment site. It also noted Sidewalk's demand that a fraction of the property taxes and development fees be retained exclusively for the Waterfront area. Normally, these revenues 
would go to the city's general coffers. Additionally, while the original bid took in only 12 acres, Sidewalk was actually requesting 350 acres (Skok, 2019).

Currently, the fate of the Waterfront Toronto Project is murky. It does not appear there is an easy resolution that will satisfy all parties. Concerns about data and its generation, collection, control, and reuse have plagued the project since its inception and have not abated since. These concerns have been compounded by Waterfront Toronto's determined resistance to transparency. At first this resistance only concerned data, but it's become increasingly clear that the company has not been forthcoming about the scope of its redevelopment plans or its attempts to retain as much of the financial benefits from the development as possible. Waterfront's post-hoc efforts at public relations have not worked either, oftentimes because they have been undermined by later disclosures. Sidwalk's attempt to cloak itself in the veil of legal privacy has done nothing to diminish its reputation among its critics as nothing more than a new-urban pirate: a stealer of public data and public land.

\section{BIBLIOGRAPHY}

Bergen, Mark. 2017. "Alphabet Looking at Toronto for 'Digital City'." Bloomberg, 11 May.

Boxikovic, Alex, and Josh O Kane. 2018. "Sidewalk Labs Reveals Toronto Neighbourhood Site Plan, Sidestepping Major Criticisms." The Globe and Mail, 3 Dec.

Cherney, Elena. 2001. "Toronto Presses On With Its Redevelopment Project for Waterfront." The Wall Street Journal, 28 Nov.
George-Cosh, David. 2017. "Alphabet's Sidewalk Labs to Create 'Smart' Neighborhood on Toronto Waterfront." Dow Jones Institutional News, 17 Oct.

George-Cosh, David, and Eliot Brown. 2017. "Alphabet's City-Building Unit Nears Development Deal in Toronto." Dow Jones NewsWire, 4 Oct.

Gray, Jeff. 2018. "Cracks Appear in Sidewalk Labs' Toronto Waterfront Plan after Fanfare; Google Affiliate's Plans for Tech Utopia Face Privacy, Development Concerns." The Globe and Mail, 23 Feb. a.

Gray, Jeff. 2018. "Sidewalk Labs Aims to Address Privacy Concerns in Designing HighTech Toronto Neighbourhood." The Globe and Mail, 20 Mar. b.

Gray, Jeff. 2018. "Talks between Google's Sidewalk Labs and Waterfront Toronto Months behind Schedule." The Globe and Mail, 2 May. c.

Kane, Josh O. 2018. "Ontario to Fire Three Waterfront Toronto Directors over Sidewalk Labs Partnership." The Globe and Mail, 6 Dec. d.

Kane, Josh O. 2018. "Ottawa and Toronto Stand by Waterfront Toronto Board." The Globe and Mail, 7 Dec. e.

Kane, Josh O. 2018. "Privacy Expert Ann Cavoukian Resigns from Sidewalk Toronto Smart-City Project: 'I Had No Other Choice'." The Globe and Mail, 20 Oct. b.

Kane, Josh O. 2018. "Sensor City: Sidewalk Labs' Toronto Project Triggers Debate over Data." The Globe and Mail, 23 Feb. $a$. 
Kane, Josh O. 2018. "Sidewalk Labs' Toronto Project Needs More Oversight, AuditorGeneral Warns." The Globe and Mail, 6 Dec. c.

McConnell, Josh. 2017. "The Android of Cities: Alphabet's Smartphone-Inspired Vision for Toronto's Waterfront." Postmedia Breaking News, 18 Oct.

"New District in Toronto Will Tackle the Challenges of Urban Growth." 2017. Canada NewsWire, 27 Oct.

Ohnsman, Alan. 2017. "Alphabet's Futuristic Urban Vision Includes Waymo 'Taxibots'." Forbes, 17 Oct.
Pringle, Ramona. 2017. "Google Plans to 'Fix' Toronto by Building Smart City." CBC News, 20 May.

Rider, David. 2017. "Google Firm Poised to Invest in High-Tech Toronto Neighbourhood." Metro News, 5 Oct.

Skok, David. 2019. "Cracks in the Sidewalk." Macleans, 20 Feb.

Waterfront Project Vision. 2017. Sidewalk Labs \& Waterfront Toronto. 